\title{
رقابة محافظو الحسابات على البنوك قواعد متميزة من أجل فعالية أكبر
}

$$
\begin{aligned}
& \text { إيمان رتيبة شويطر } \\
& \text { كلية الحقوق } \\
& \text { جامعة الإخوة منتوري } \\
& \text { قسنطينة }
\end{aligned}
$$

$$
\begin{aligned}
& \text { ملخص: } \\
& \text { يلعب محافظ الحسابات دورا فعالا ومتميز ا في الرقابة }
\end{aligned}
$$

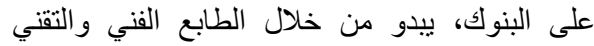

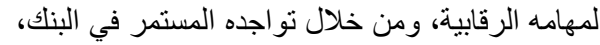

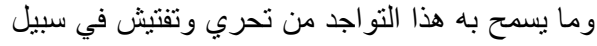

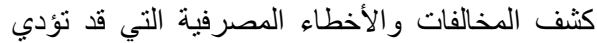

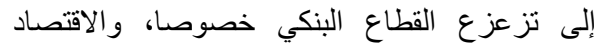

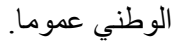

$$
\begin{aligned}
& \text { وبالرغم من الدور الذي يمارسه محافظ الحسابات، إلا }
\end{aligned}
$$

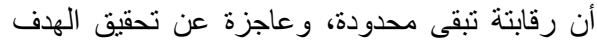

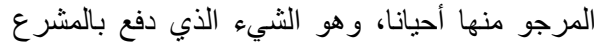

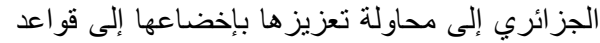

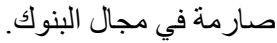

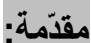

لقد أدت الهزات البنكية التي

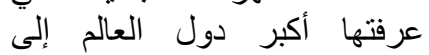
إضعاف الثقة التي تقوم عليها لتوليها

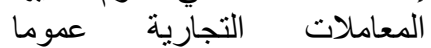

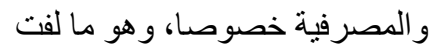

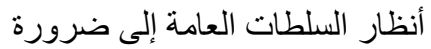

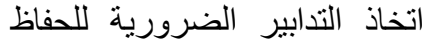
على حقوق المودعين و المستثمرين وبالتالي على قدرة الدولة والثقة

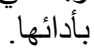
وفي سـبيل ذلكـ أصسرت معظم الدول ومن بينها الجز ائر تشريعات التشات خاصة بمر اقبة النشاطات الحساستة

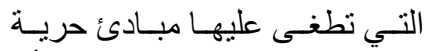

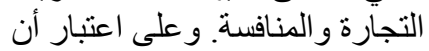
النشاط المصرفي بعد أحد أهم هاته أنها النشاطات التي يرتكز عليها القطاع الهاع

\section{Abstract :}

The governor's accounts plays a noticeable and effective role in the censorship over the banks through the technical censorship tastes and well as his constant presence in the bank ,This presence allows the inspection which disclose the irregularities and the banking errors which lead to the shaking of the banking sector in particular and the National economy in general. despite the role that the governor's accounts exerts ,this censorship is limited and powerless sometimes to achieve the intended target.

Consequently, the algerian legislators attempts to reinforce the censorship through subjugating it to rigorous rules in the banking field. 


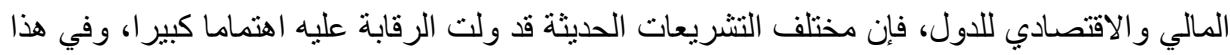

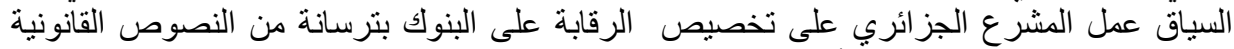
و التنظيمية التي تجد مصدرهاً أساسا في التوصيات التي جاءت بهات بها لجنة بازل للرقابة الدصرفية (1) الفعالة)

ويقصد بالرقابة المصرفية سلطة التاكد و التفنيش عن مدى قانونية ونظامية العطليات و النشاطات التي

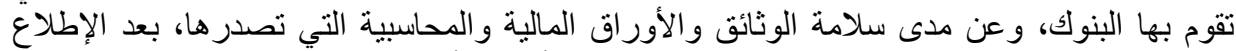

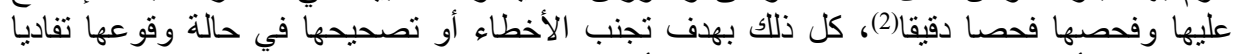

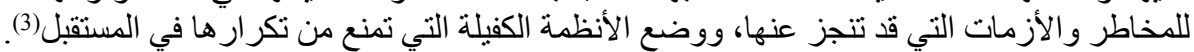

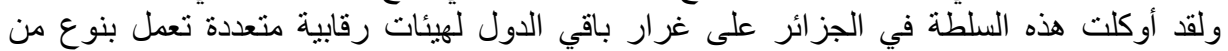

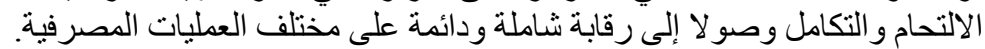

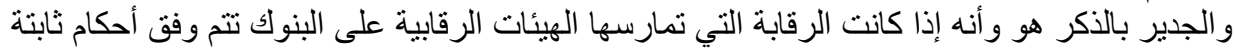

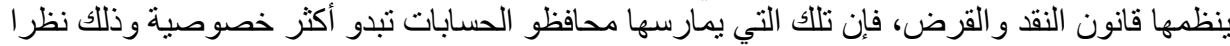

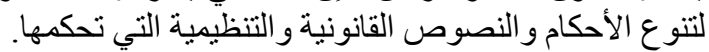

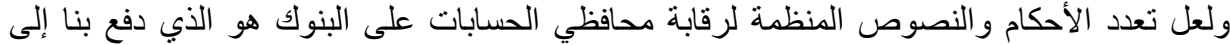

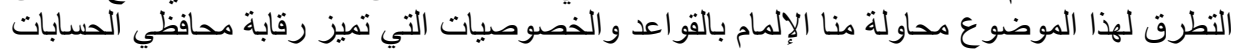

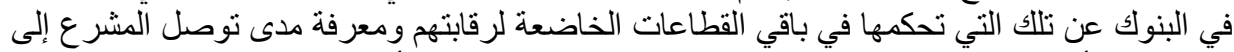

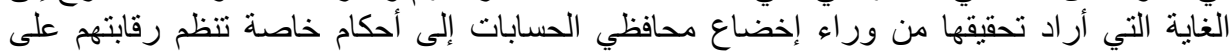

المطلب 1: خصوصيات تعيين ورقابة محافظ الحسابات على البنوك

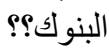

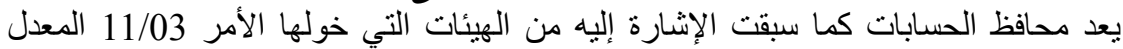

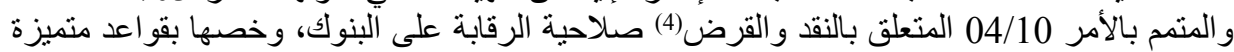

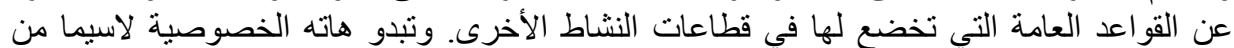

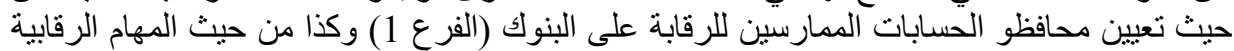

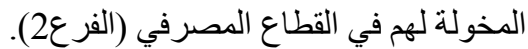

الفرع 1: تعيين محافظو الحسابات المكلفون بالرقابة على البنابنو

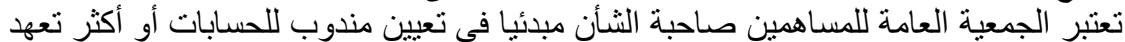

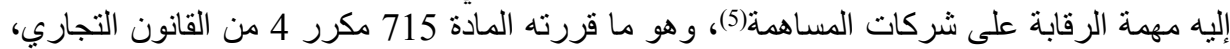

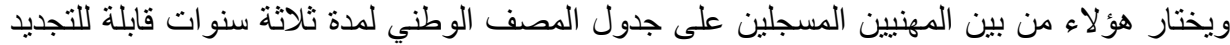

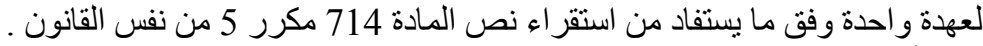

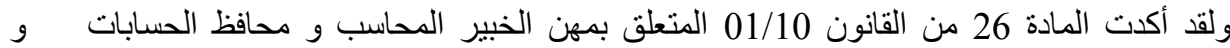

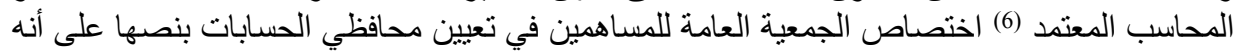

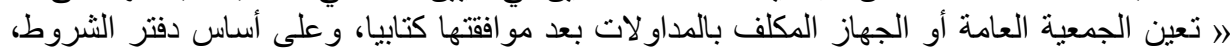

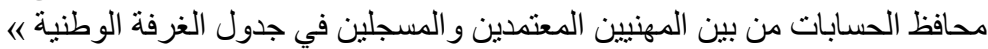

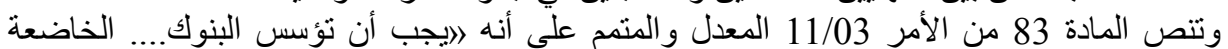

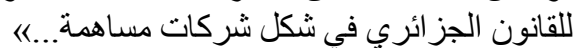

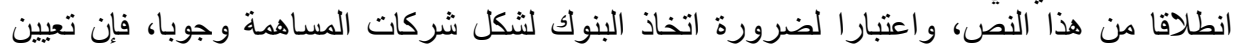

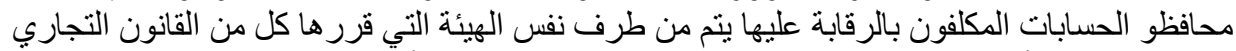

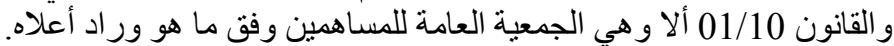

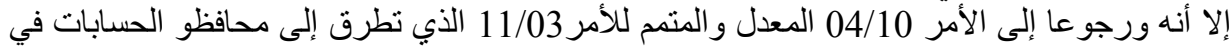

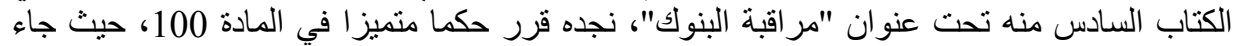

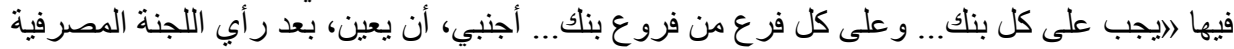


و على أساس المقاييس التي تحددها، محافظين (2) للحسابات على الأقل مسجلين في قائمة نقابة الخبراء

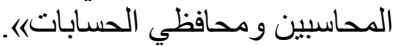

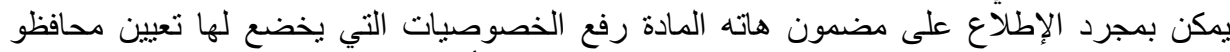
الحسابات على مستوى البنوك، و التي يمكن حصر ها في في نقطتين أساسيتين.

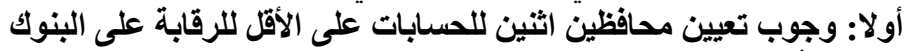

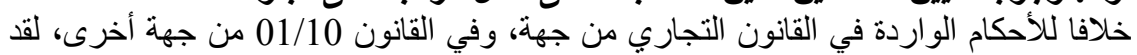

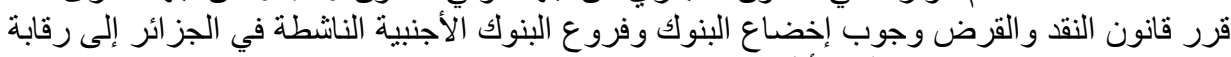
محافظي حسابات اثثين (2) على الأقل .

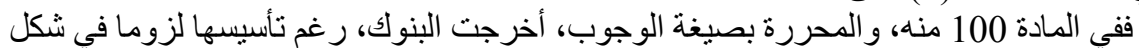

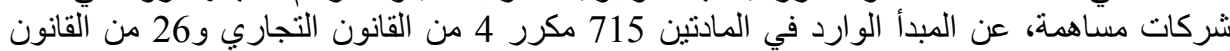

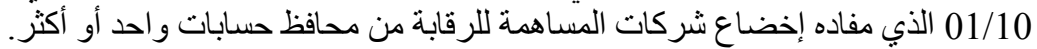

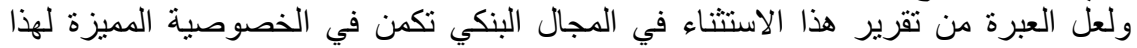

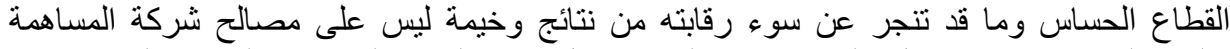

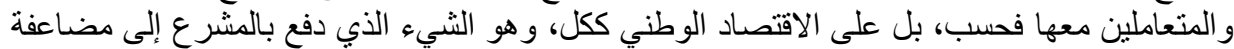

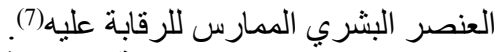

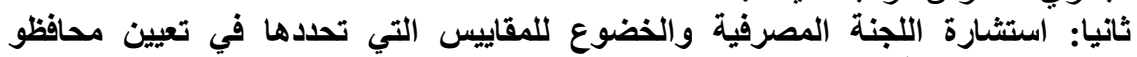
الحسابات المكلفون بالرقابة على البنوك الجنية

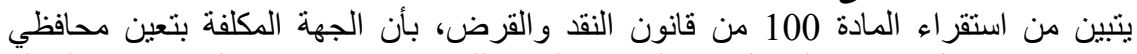

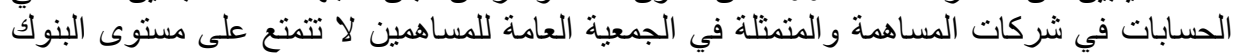

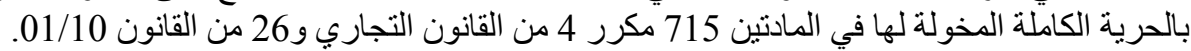

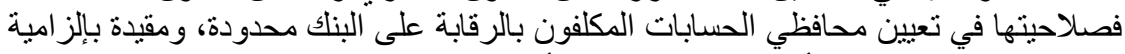

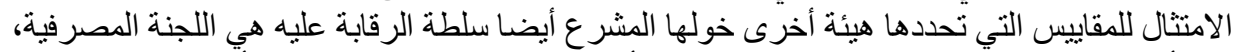

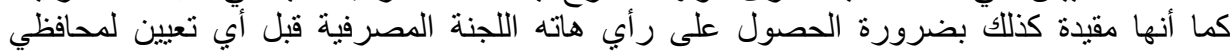
الحسابات أنها

فعلى مؤسسة القرض المعنبة أن تخبر مسبقا اللجنة المصرفية بأسماء محافظي الحسابات الذين التئي

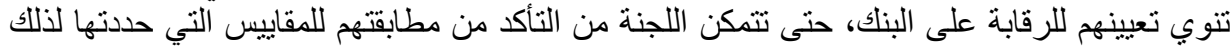

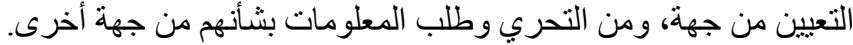

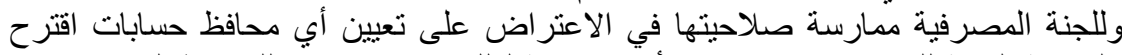

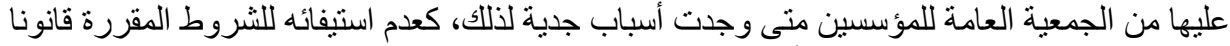

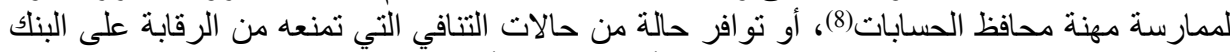

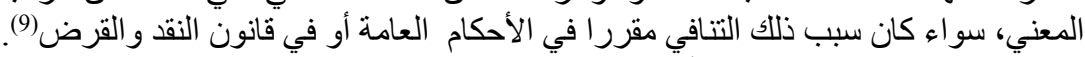

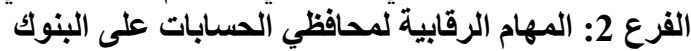

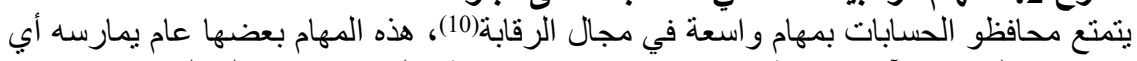

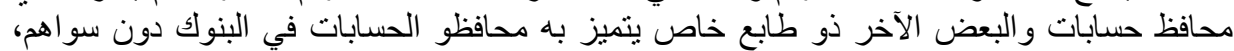

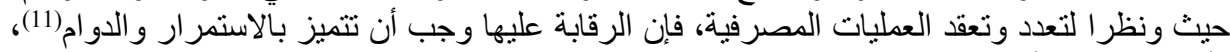

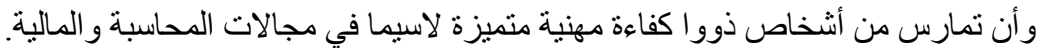

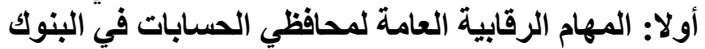

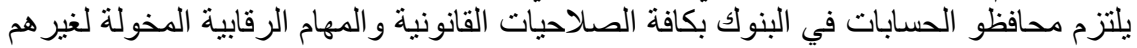

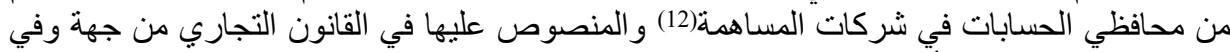

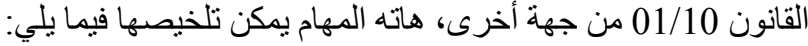
- إثبات شر عية وصدق الحسابات من خلال التحقيق و التفنيش في الدفاتر و الأور اق المالية للبنك، 
مر اقبة انتظام حساباته وصحتها، بالإضافة إلى التدقيق في صحة المعلومات التوات التي تتضمنها التقارير

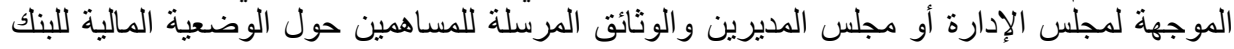

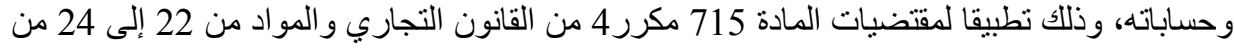

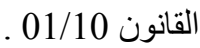

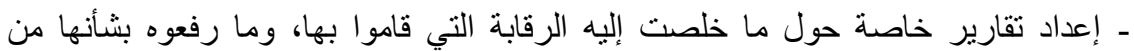

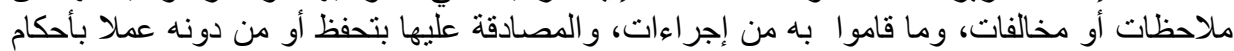

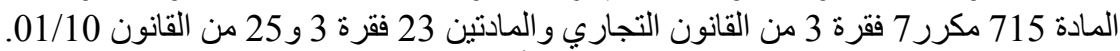

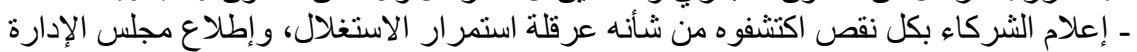

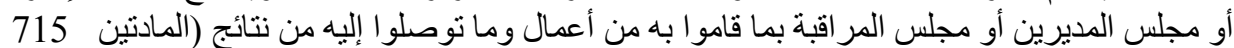

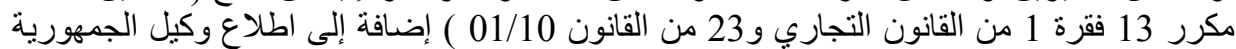

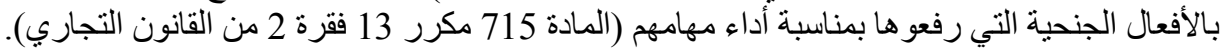

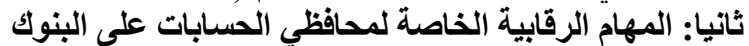

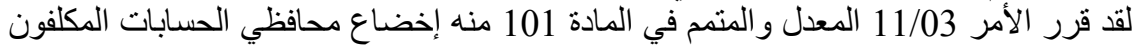

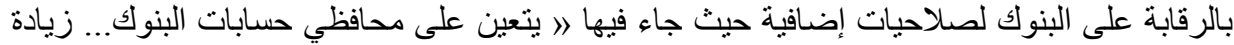
على التز اماتهم القانونية، القيام بمأ بأتي:

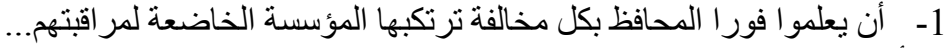

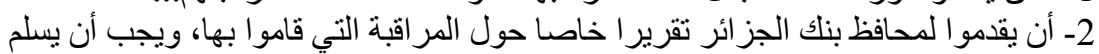

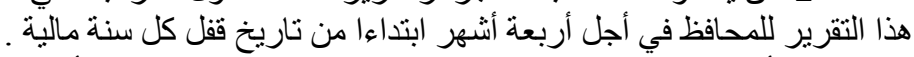

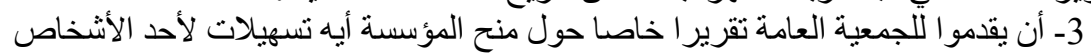

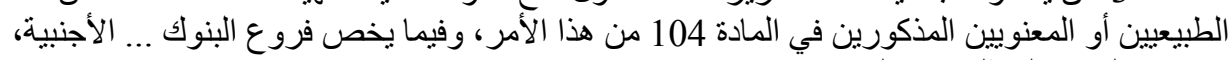
يقدم هذا التقرير لمثنليها في الجزائر.

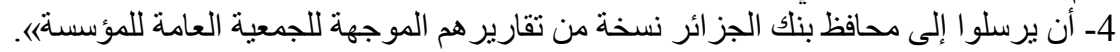

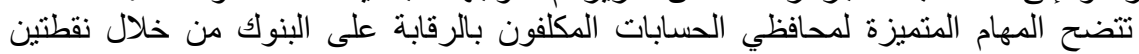

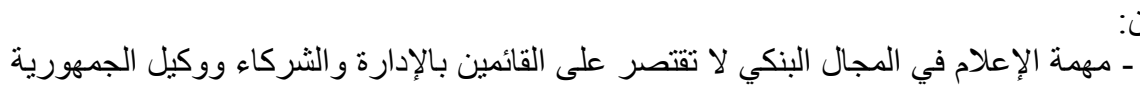

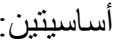

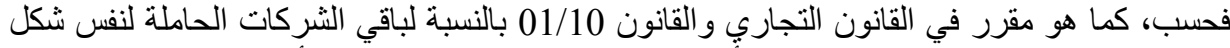

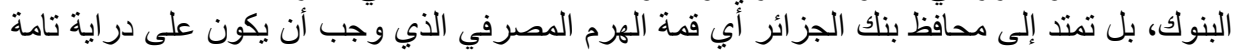
وكافية و فورية بالثؤون البنكية ونتائج الرقابة علية الئها، وبكل مخالفة ارتكبت من البنائك محل الرقابة،

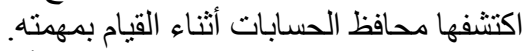

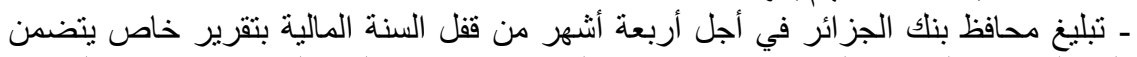

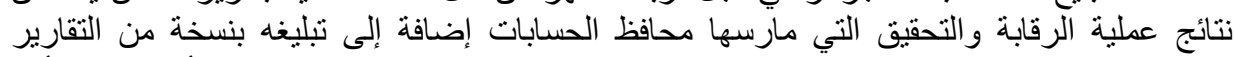

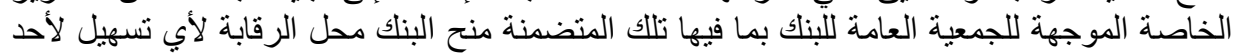

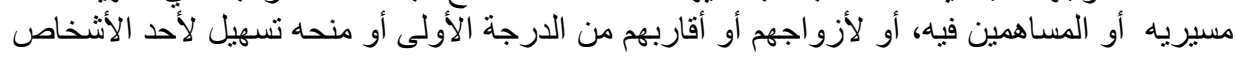

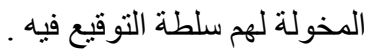

المطلب 2: تدعيم مهام محافظو الحسابات على البنوك والرقابة عليها

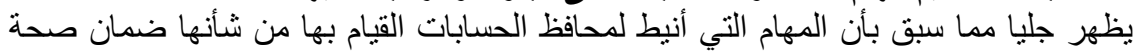

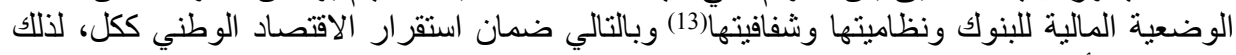

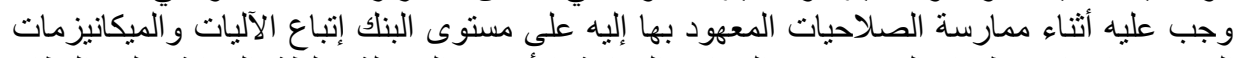

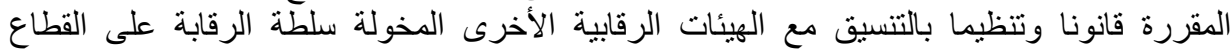

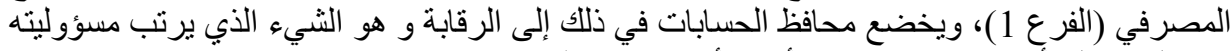
عن كل إخلال أو تقصير صادر منه مأنثاء تأدية مهامه (الفرع 2). 
الفرع 1: التنسيق بين محافظي الحسابات والهيئات الأخرى المخولة بسلطة الرقابة على

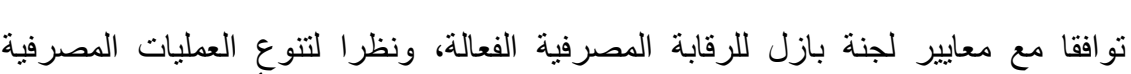

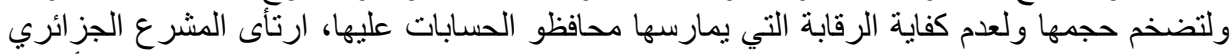

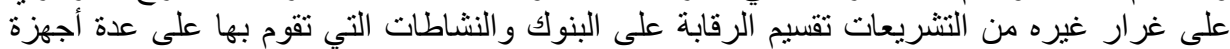

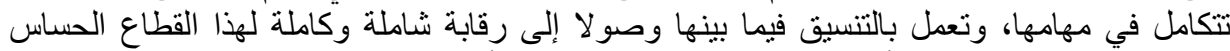
وتفاديا لهاً قد تتجر عن سوء أو نقص رقابته من نتائج وخيمة وأزمات

\section{أولا: التنسيق مع اللجنة المصرفية}

لا تقتصر اللجنة المصرفية على تحديد المقاييس التي يخضع لهي لها تعيين محافظي الحسابات،

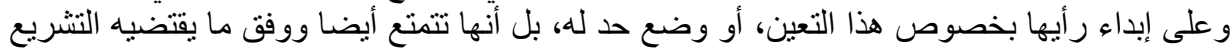

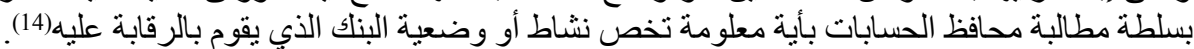

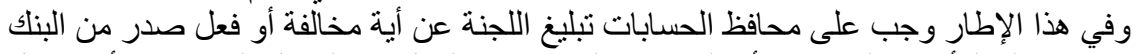

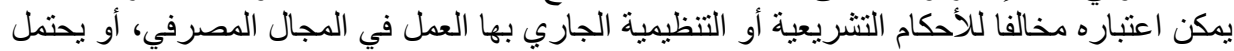

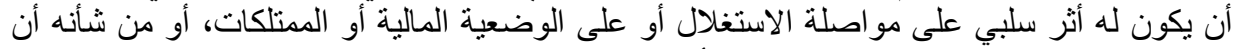

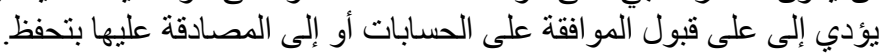

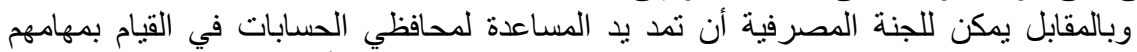

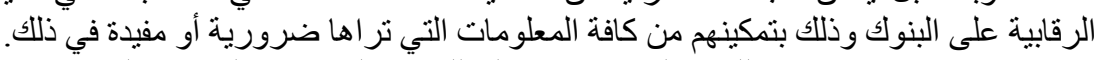

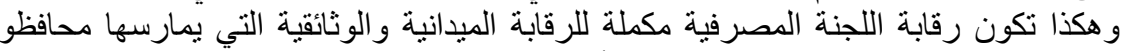

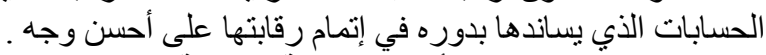

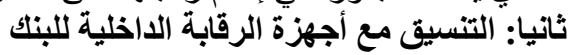

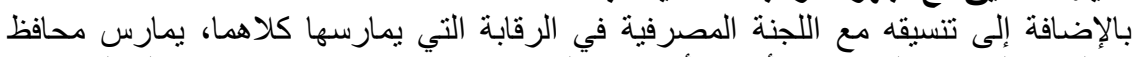

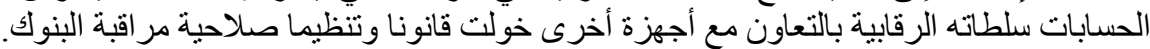

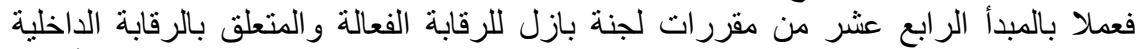

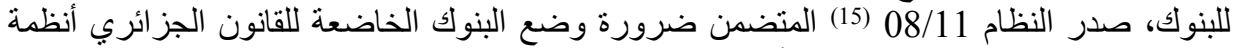

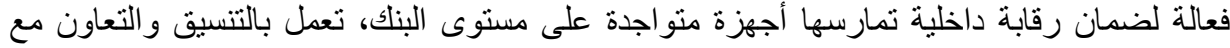

$$
\begin{aligned}
& \text { محافظي الحسابات (المادة } 73 \text { من النظام ) فئلة } \\
& \text { و تتمثل هاته الأجهزة في : }
\end{aligned}
$$

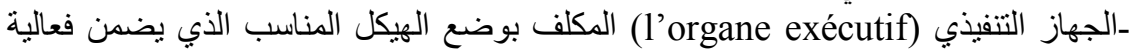

$$
\text { الرقابة الداخلية بتحديد النشاط الرقابي على كل المستويات العملية في البناك. }
$$

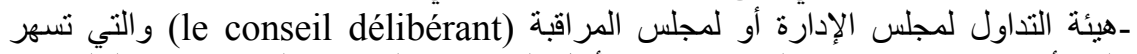

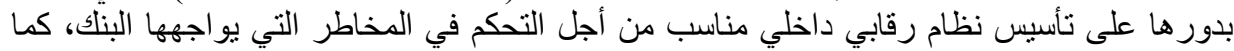

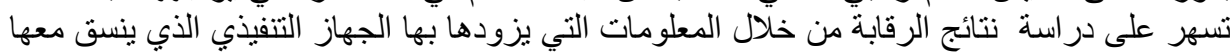

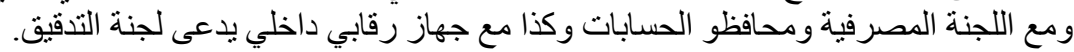

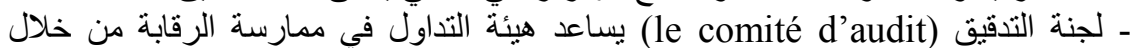
التحقق من دقة المعلومات المحاسبية وتقدير المناهج المحاسبية للبنك ومراقبة فئة عملياته الإستراتيجية هن خلية

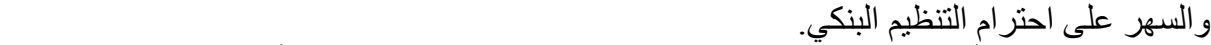
كل هاته الأجهزة تسهر بالتنسيق مع محافظو الحسابات على ضمان التهان أحسن رقابة على القطاع

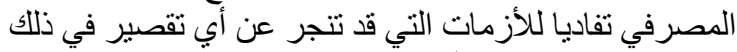

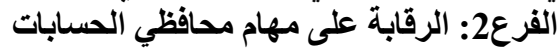

يخضع محافظو الحسابات في قيامهم بالرقابة على البنوك إلى مراقبة جهاز خوله قانون النقد 
و القرض صلاحية القيام بذلك هو اللجنة المصرفية، التي يمكنها تسليط العقوبات المقررة قانونا عليه في إلي حالة ثبوت مسؤوليته أو إخفاقه في أداء المهام المبام المعهود بها المها إليه.

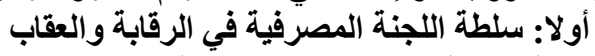

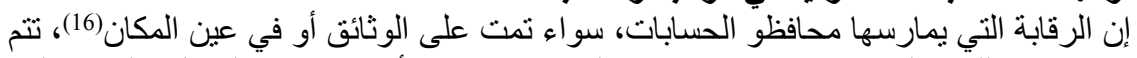

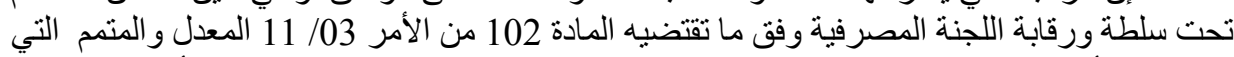

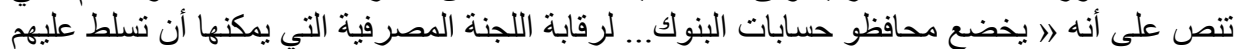
العقوبات الآتية، دون الإخلا بخل بالملاحقات التأديبية أو الجزائية : لأبرابة

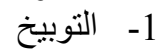
2- - المنع من مو اصلة عمليات مر اقبة بنك ما....

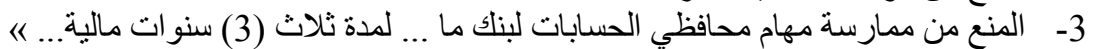

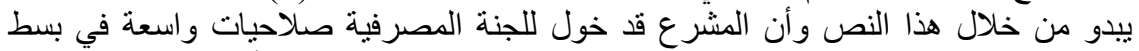

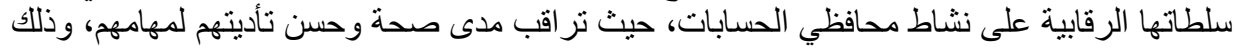
من خلال التقارير التي يوجهها هؤلاء لمحافظ بنك الجزائر الذي يعد في آن واحد رئيس اللجنة

حيث وكما سبقت الإشارة إليه آنفا يلتزم محافظو الحسابات بإعلام محافظ بنك الجزائر بأية المصر فية(17) منالت

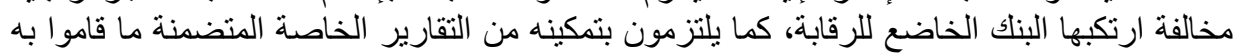

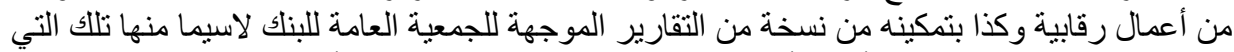

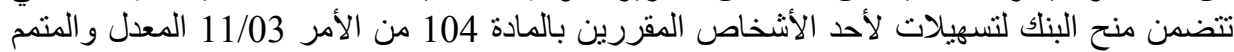

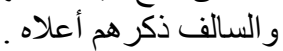
وتبدو أهمية إبلاغ محافظ بنلك الجزائر لما توصل إليه محافظو الحسابات من نتائج إثر رقابتهم،

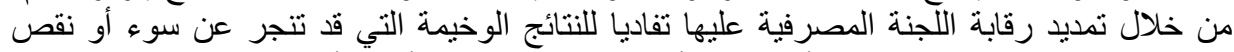

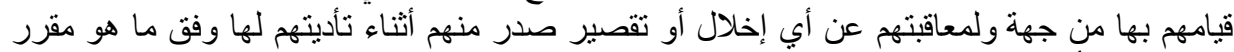
بالمادة 102 أعلاه.

ولقد عززت السلطة الرقابية والعقابية للجنة المصرفية على محافظو الحسابات بحكم المادة 136

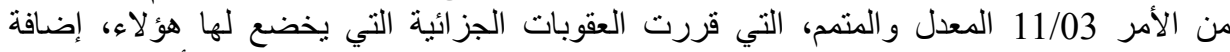
للعقوبات التي قد تخضعها إليهم اللجنة المصرفية عملا بمقتضيات المادة 102 من نفس المس الأمر.

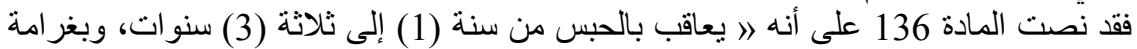

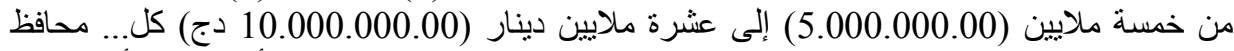

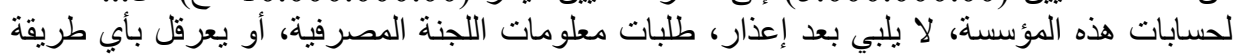

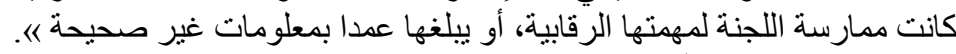
ثانيا: مسؤولية محافظو الحسابات

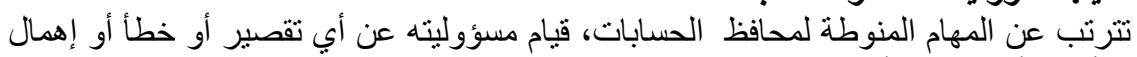

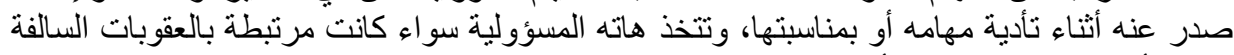

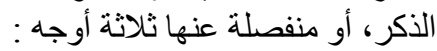

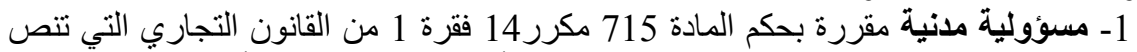

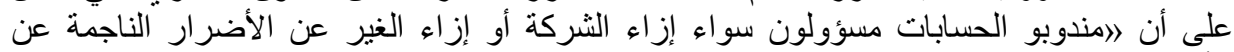

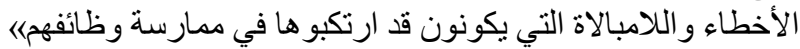

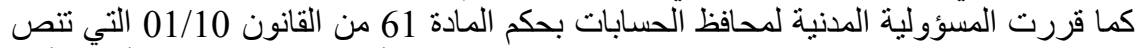
على أنه اليعد محافظ الحسابات مسؤولا تجاه الكيان المراقب عن الأخطاء التي يرتكبها أنثاء تأدية ويعد متضامنا تجاه الكيان أو تجاه الغير عن كل ضرر ينتج عن مخالفة أحكام هذا القانون ولا 
يتبرأ من مسؤوليته فيما يخص المخالفات التي لم يشترك فيها إلا أذا أنتبت أنه قام بالمنطلبات العادية

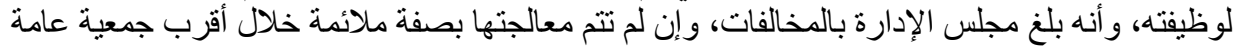

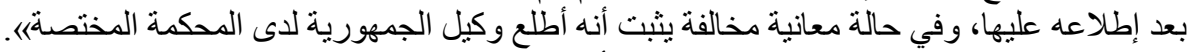

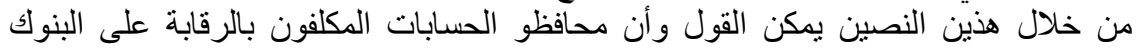

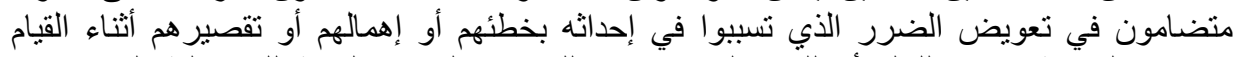

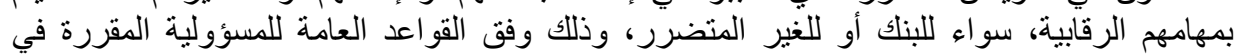
القانون الددني وفي الأحكام العامة.

2- مسؤولية جزائية مقررة بموجب المادة 62 من القانون 01/10 التي تتص على على أنه

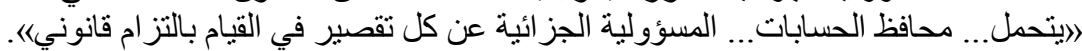

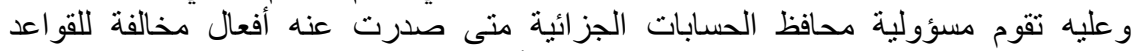

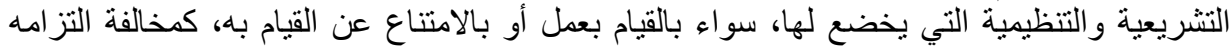

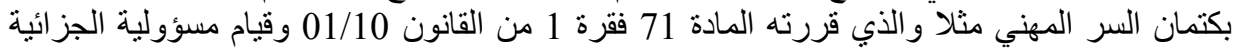

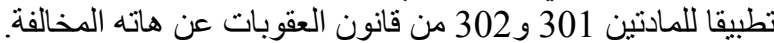

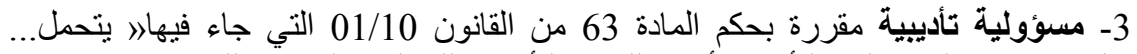

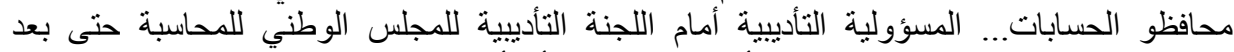

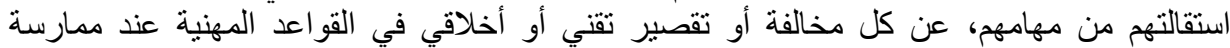
وتتخذ اللجنة التأديبية إحدى العقوبات التي قررنها الفقرة الثانية من المادة 63 أعلاه و المرتبة وظائفهم......

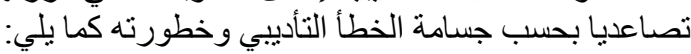

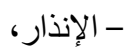

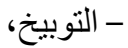
- التوقيف لمدة أقصاها ستة (6)أشهر و الثشب من الجدول .

\section{خاتمة:}

خلاصة لما سبق نتوصل إلى القول بأن المشرع الجز ائري كانت له نية واضحة ور غبة عمية عميقة

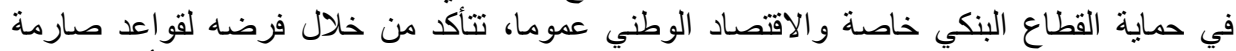

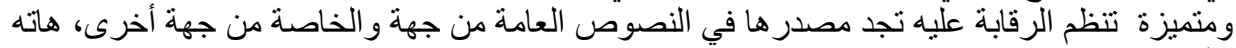

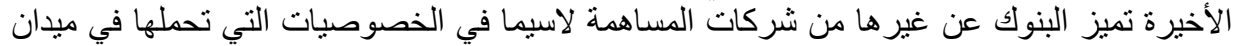

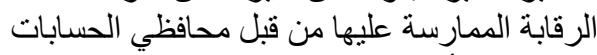

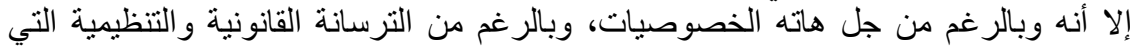

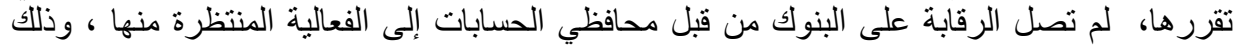

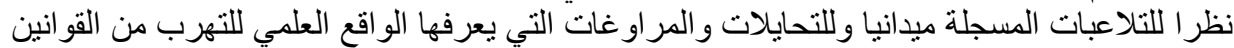

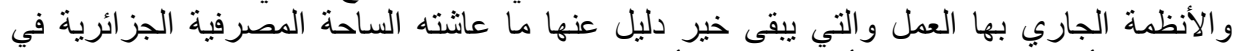

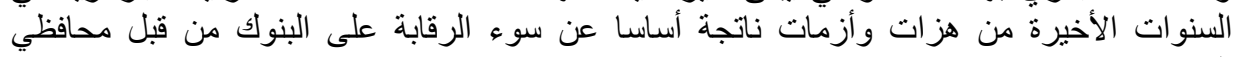

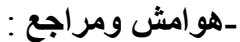

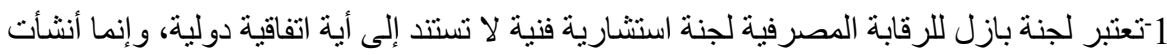

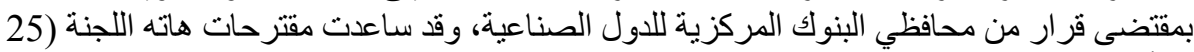

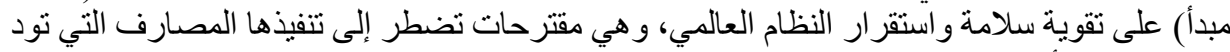
الخروج إلى الأسواق العالمية. 
2- فضيلة ملهاق، وقاية النظام البنكي الجزائري من تبيض الأمو ال، دار هومة للطباعة و النشر

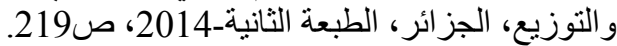

3-عبد الكريم طبار، الرقابة المصرفية، ديو ان المطبو عات الجامعية، الجزائر ، الطبعة الثانية-1988،

ص6.

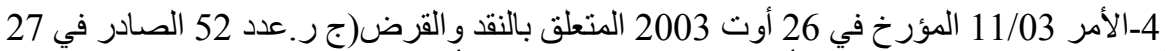

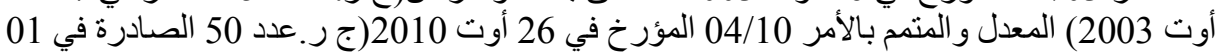

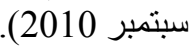

5-Mémento pratique Francis LEFEBVRE, Droit des affaires, Sociétés Commerciales, édition Francis LEFEBVRE, 2013, P54

$$
\begin{aligned}
& \text { 6-القانون 01/10 المؤرخ في } 29 \text { جوان } 2010 \text { المنعلق بمهن الخبير المحاسب ومحافظ الحسابات } \\
& \text { و المحاسب المعتمد (ج.ر عدد } 42 \text { الصادرة في } 11 \text { جويلية 2010). }
\end{aligned}
$$

7- KPMG, Guide des banques et des établissements financiers en Algérie, KPMG Algérie , 2012, P96 édition

$$
\begin{aligned}
& \text { 8-أنظر المادة } 8 \text { من القانون 01/10 التي حددت شروط تعيين شخص طبيعي كمحافظ للحسابات و المادة }
\end{aligned}
$$

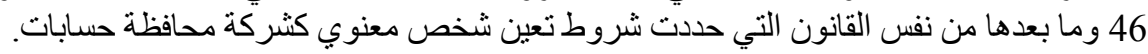

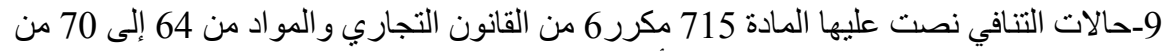

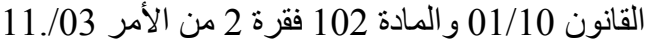

10-RIPERT.G \& ROBLOT.R, Traité de droit commercial, Tome 2, Droit commercial et des société, par Germain. M \& MAGNIER.V, LGDJ , 20 ème édition, 2011, P670

$$
\text { 11-عجرود وفاء، اللجنة المصرفية وضبط النشاط المصرفي، دار الحامد للنشر والتوزيع، الأردن، }
$$

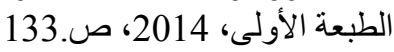

12-Mémento pratique FRANCIS LEFEBVRE, Droit des affaires, Sociétés commerciales , édition FRANCIS LEFEBVRE ,2000, p705.

13-DEKEUWER- DEFOSSEZ.F \& MOREIL.S , Droit Bancaire, $10^{\mathrm{e}}$ édition, 2010, MEMENTOS DALLOZ, P96

$$
\begin{aligned}
& \text { 14-الطاهر لطرش، تقنبات البنوك، ديوان المطبو عات الجامعية، الطبعة السابعة، 2010، ص205. } \\
& \text { 15-النظام 08/11 المؤرخ في } 28 \text { نوفمبر } 2011 \text { المنتعلق بالرقابة الداخلية للبنوك و المؤسسات المالية }
\end{aligned}
$$

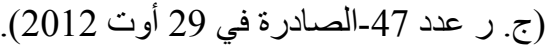

$$
\begin{aligned}
& \text { 16-أنظر المادتين } 31 \text { و } 32 \text { من القانون 10 10 }
\end{aligned}
$$

17-Thierry BONNEAU , Droit bancaire, MONCHRETIEN, $5^{\text {éne }}$ édition,2003,p173 